\title{
ERRATUM
}

\section{REVISTA FAMECOS - EDIÇÃO V. 26, N. 2 (2019)}

A Equipe Editorial da Revista FAMECOS torna publica as seguintes alteração e substituição, na edição v. 26, n. 2 (2019), DOI: http://dx.doi.org/10.15448/19803729.2019.2, ID 32229, artigo, Tempo, mídia e processos sociopolíticos no Brasil do século XXI: Perspectivas sociossemióticas.

Primeiro parágrafo, pág. 3 Onde se lê "Com base em um diálogo..." leia-se: “Como apontam estudiosos de diversa extração disciplinar, a trajetória que levou, em agosto de 2016, ao impeachment da ex-presidente do Brasil Dilma Rousseff, tem seu ponto de partida naquelas que são hoje conhecidas como as "Jornadas de Junho de 2013" (Nobre, 2013; Bucci, 2016; Singer, 2018)."

Segundo parágrafo, pág. 3, $1^{\mathrm{a}}$ linha - Excluir a primeira frase, entre: "Como apontam estudiosos [...] (NOBRE, 2013; BUCCI, 2016; SINGER, 2018)”.

Pág. 3, $3^{\circ}$ parágrafo, $7^{\mathrm{a}}$ linha - Onde se lê: Como procurei mostrar em outras ocasiões, essas últimas contribuem a alimentar tanto a nevoeiro de significados quanto a projeção federal das jornadas, traçando o perfil de um Brasil abalado, cujo futuro estaria cada vez mais incerto (SCHWARZ, 2013)", leia-se: Como procurei mostrar em outras ocasiões (Demuru, 2019), estas últimas contribuem a alimentar tanto o nevoeiro de significados quanto a projeção federal das jornadas, traçando o perfil de um Brasil abalado, cujo futuro estaria cada vez mais incerto (cf. Schwarz, 2013).

Pág. 4, $2^{\circ}$ parágrafo, $4^{\mathrm{a}}$ linha - Onde se lê: [...] SOUZA, 2016; BUCCI, 2016; SINGER, 2018), pouco se discutiu e pouco se discute, ainda, sobre [...], leia-se: [...] Souza, 2016; Bucci, 2016; Singer, 2018; Prado, 2018), poucos são os trabalhos que discutem [...]. 
Pág. 4, $3^{\circ}$ parágrafo, $4^{\mathrm{a}}$ linha - Onde se lê: [...] Quais são as diferenças entre o tempo das novas e das velhas mídias?, leia-se: Quais são as diferenças entre o tempo das novas (a internet e as redes sociais) e das velhas mídias (televisão, rádio, mídia impressa)?

Pág. 4, $4^{\circ}$ parágrafo, $5^{\mathrm{a}}$ linha - Onde se lê: [...] da Comunicação (CASTELLS, 2005; BARBOSA, 2017), leia-se: [...] da Comunicação (Castells, 2005; Malini, 2016; Fausto Neto, 2016; Barbosa, 2017; Prado, 2018).

Pág. 4, $5^{\circ}$ parágrafo, $8^{a}$ linha. Onde se lê: [...]Entretanto, como defendo aqui, os dois [...]mesma moeda, leia-se: Como defendo, trata-se de níveis de conceptualização teórico-metodológica que merecem uma abordagem conjunta.

Pág. 5, $2^{\circ}$ parágrafo, $14^{a}$ linha - Onde se lê: [...] dimensão sensível. Como veremos, [...], leia-se: [...] dimensão sensível. Como defendo, [...].

Pág. 5, $\mathbf{2}^{\circ}$ parágrafo, item "a" - Onde se lê: a) as jornadas de junho de 2013 constituem um acontecimento acidental/explosivo que faz colapsar o sistema de crenças e valores do lulismo - "o ressurgimento, no horizonte, de um país com algum futuro" (Nobre, 2013, não paginado), de um País menos desigual e mais desenvolvido (SCHWARZ, 2013; SINGER, 2018; SOUZA, 2016; BUCCI, 2016) - dando vida a um momento histórico imprevisível, o qual se estende até o impeachment de Dilma Rousseff e, pode-se presumir, às eleições presidenciais de 2018, embora não haja espaço para abordar, aqui, esta segunda fase do processo; leia-se: a) as jornadas de junho de 2013 constituem, no quadro da recente história política brasileira, um acontecimento acidental/explosivo disruptivo; um acontecimento, ou seja, que faz colapsar o sistema de crenças e valores do lulismo - "o ressurgimento, no horizonte, de um país com algum futuro" (Nobre, 2013, doc. não paginado), de um país "menos desigual" e "mais desenvolvido" (cf. Schwarz, 2013; Singer, 2018; Souza, 2016; Bucci, 2016) - dando vida a um momento histórico imprevisível, o qual se estende até o impeachment de Dilma Rousseff e, pode-se presumir, às eleições presidenciais de 2018, embora não haja espaço para abordar, aqui, esta segunda fase do processo;

Pág. 5, $\mathbf{2}^{\circ}$ parágrafo, item "b" - Onde se lê: b) o regime temporal ao qual dá origem essa explosão distingue-se pela valorização paroxística da imediatez e pela alternância serializada de acontecimentos pontuais em relação entre si um regime que, parafraseando Hartog, poder-se-ia definir "hiperpresentista" (HARTOG, 2015, p. XV); Leia-se: b) o regime temporal, ao qual dá origem essa 
explosão, distingue-se pela valorização paroxística da imediatez e pela alternância serializada de acontecimentos pontuais em relação entre si - um regime que, parafraseando Hartog (2015, p. XV), chamarei aqui de "hipepresentismo fractal".

Pág. 5, $3^{\circ}$ parágrafo, $2^{\mathrm{a}}$ linha - Onde se lê: [...]processos sociopolíticos em ato, no Brasil [...], leia-se: [...]processos sociopolíticos e midiáticos em ato, no Brasil [...].

Pág. 5, ao final do $3^{\circ}$ parágrafo, $30^{\mathrm{a}}$ linha - acrescentar subtítulo "Premissas teórico-metodológicas", seguido pelo texto:

As releituras teóricas das noções de acidente e explosão e as hipóteses elencadas na Introdução do artigo serão desenvolvidas a partir da análise de um conjunto de textos diversos - verbais, imagéticos, audiovisuais, etc. - extraídos tanto do universo da velha mídia (telejornais, capas de jornais e revistas, programas radiofónicos), quanto daquele das redes sociais digitais (Twitter e Facebook em particular). Além disso, contemplam-se eventos políticos propriamente ditos, entre os quais as manifestações de rua e as sessões de votação no Congresso Nacional, como a do Impeachment de ex-presidente na Câmara dos Deputados. Precisa-se que tal escolha reflete uma atitude epistemológica e teórico-metodológica própria da sociossemiótica e da semiótica da cultura contemporâneas (SEDDA, 2012; LANDOWSKI, 2017). Como tive oportunidade de discutir mais a fundo em outras ocasiões (DEMURU, 2018a), quem pretende abordar os processos sociais e o político-mediáticos de um ponto de vista semiótico deve-se engajar na construção de corpora diversificados, procurando estabelecer séries de relações (FOUCAULT, 1969; SEDDA, 2012) entre textos e discursos variados e aparentemente distantes uns dos outros (a capa de um jornal, um tweet, uma série de tweets, um protesto de rua, uma estratégia global de comunicação política, o discurso sobre um modelo de país). Trata-se de um passo fundamental para desvendar as engrenagens que regem o devir dos processos comunicacionais e midiáticos na era da sociedade e da política em rede (CASTELLS, 2005; DAL LAGO, 2017), inclusive seus devires temporais.

Para tanto, a análise será conduzida a partir do arcabouço conceitual do Percurso Gerativo de Sentido de Greimas (GREIMAS; COURTÉS, 2008), do modelo dos Regimes de Sentido e Interação de Landowski (2014) e das postulações de Lotman sobre a semiosfera e a explosão (LOTMAN, 1985; 1995; 2009), em diálogo com as pesquisas atuais sobre a temporalidade midiática (CASTELLS, 2005; HARTOG, 2015; BARBOSA, 2017; FAUSTO NETO, 2016; PRADO, 2018) e as interações entre 
o campo midiático e o campo político desenvolvidas na área de comunicação (RODRIGUES, 1999; MIGUEL, 2002; FAUSTO NETO, 2008; 2012; 2016; BRAGA; 2012). Tanto Greimas, quanto Landowski e Lotman nos fornecem, nesse sentido, instrumentos heurísticos para buscarmos e descrevermos os elos - ou melhor, nos termos de Greimas, as “isotopias” (GREIMAS, COURTÉS, 2008, p. 275) - entre as diversas semiosferas da sociedade brasileira, em particular, aquelas entre a semiosfera midiática e política.

Seguindo as diretrizes traçadas por Lotman (1985; 2009) e Landowski (2014; 2018), entendo, aqui, as semiosferas midiáticas e políticas como campos semiótico-discursivos, regidos por linguagens e práticas interacionais diversas e específicas, bem como por tensões e relações de força a partir das quais se constroem, definem e redefinem as identidades dos sujeitos sociais - tensões e relações que, de um ponto de vista semiótico, são sempre tensões e relações de sentido. Da primeira fazem parte as mídias tradicionais (a televisão, a mídia impressa, o rádio) e as novas mídias digitais (as redes sociais e a internet de modo geral), cujas lógicas, como veremos na análise, embora diferentes, tendem a se sobrepor. A segunda é composta por textos, discursos e atos tanto da política institucionalmente reconhecida (presidentes, ministros, líderes, partidos, organizações, etc.), quanto daquela mais fluida dos movimentos e das manifestações populares (termo que, vale lembrar, é necessário entender e utilizar com a devida dose de ceticismo crítico-científico).

Tal concepção guarda semelhanças com os conceitos de campo social, político e midiático desenvolvidos no âmbito das ciências sociais e da comunicação. Pense-se, a este propósito, nas propostas de Rodrigues (1999, p. 18) que entende o campo social e midiático não num sentido espacial, mas "energético, à maneira da física, que fala de campo de forças para designar a tensão gerada pelo confronto entre polos de sentido oposto". Ou, ainda, nas releituras do conceito de campo de Bourdieu proposta por Miguel (2002) a fim de refletir sobre as tensões internas e externas aos campos político e midiático, bem como nos estudos mais recentes sobre as lógicas da midiatização e da circulação de Braga (2012) e Fausto Neto (2008; 2012; 2016).

No entanto, como tais estudos sugerem - e como faz questão de evidenciar a perspectiva semiótica, seja aquela greimasiana e pós-greimasiana, seja aquela lotmaniana -, mais do que a suposta autonomia (RODRIGUES, 1999) de cada semiosfera ou campo, o que importa são as relações que elas entretêm entre si. 
Como Lotman não se cansava de lembrar, "nenhum sistema de signos possui um mecanismo que lhe permita funcionar isoladamente" (LOTMAN, 2006, p. 131, trad. minha)'. É a partir destas relações que se definem as lógicas específicas de cada semiosfera - no nosso caso, as semiosferas política e midiática - e as identidade dos sujeitos sociais que as atravessam e as disputam. E é a partir da ação conjunta das tensões entre as semiosferas midiática e política que se produz, como veremos, a temporalidade hiperpresentista que caracteriza a nossa contemporaneidade.

Antes de entrar no vivo da análise, vejamos, porém, como se definem e podem ser interdefinidos os conceitos de acidente e explosão propostos, respectivamente, por Landowski e Lotman.

Pág. 5, $4^{\circ}$ parágrafo - Entre "Quatro são os regimes identificados por Landowski: programação, manipulação, ajustamento e acidente" e "Entretanto, o que me interessa debater não é a lógica geral do modelo landowskiano, mas sim as dimensões aspectuais-temporais (Greimas \& Courtés, 2008, p. 39-40) próprias do regime do acidente", leia-se: Quatro são os regimes identificados por Landowski: a programação, fundada na lógica da regularidade e da rotina; a manipulação, baseada em uma intencionalidade de tipo estratégico, cujo fim é a adesão, por parte do sujeito manipulado, a valores e programas previamente estabelecidos por um dado destinador; o ajustamento, no qual não existem esquemas de ações prefixados, sendo que os interagentes ajustam-se uns aos outros a partir de uma competência de tipo estésico, ou seja, sensível; e, por fim o acidente, regido pela lógica do alea. É o regime da insensatez, no qual o acaso irrompe em sua forma mais pura, como no caso de tsunami, raios, terremotos ou mesmo de imprevistos felizes, de golpes de sortes inesperados (Landowski, 2014, p. 71).

Entretanto, o que me interessa debater não é a lógica geral do modelo landowskiano, mas sim as dimensões aspectuais-temporais (Greimas \& Courtés, 2008, p. 39-40) próprias do regime do acidente.

A este propósito, três são as linhas de raciocínio que é relevante e oportuno desenvolver.

Antes de mais nada, pode-se assumir, com base na teoria dos aspectos desenvolvida por Greimas (Greimas \& Courtés, 2008, p. 39-40), que o acidente seja

" "Nessun sistema semiotico possiede un meccanismo che gli consenta di funzionare isolatamente" (Lotman, 2006, p. 131). 
um acontecimento pontual ao mesmo tempo terminativo e incoativo, isto é, um evento que marca tanto o fim do velho (aspecto terminativo) quanto o começo do novo (aspecto incoativo). Esta leitura justifica-se por uma razão precisa, que tange à denominação dos papeis narrativos que o semioticista francês atribui ao acidente. Diferentemente da programação, cujo papel é assimilável ao papel temático da gramática narrativa greimasiana (cf. Greimas \& Courtés, 2008, p. 496), o acidente cumpre, afirma Landowski, dois papeis: um "papel catastrófico" (de algo que rompe com a cadeia sedimenta dos eventos) e um "papel catalítico" (de algo que engendra um novo ciclo, cujas trajetórias são, no momento no qual se manifesta, ainda imprevisíveis) (cf. Landowski, 2014, p. 79).

Em segundo lugar, parece-me profícuo estabelecer uma correlação entre a valorização aspectual (pontual/terminativa e pontual/incoativa) do acidente e a problemática da estesia por ele desenvolvida no âmbito da reflexão sobre o regime do ajustamento. É o que havia feito Greimas em Da Imperfeição (2002) ao abordar a problemática do acidente estético, entendido como uma fratura da rotina cotidiana de matriz eminentemente sensível ${ }^{2}$. Seguindo tais as indicações, proponho pensar o acidente sociossemiótico como um acontecimento suscetível de engendrar uma cadeia de reações sensíveis nos contextos nos quais se verifica. Isso é evidente no caso de acidentes políticos. Por exemplo, todas as primaveras que marcaram a segunda década do século $X X I$, tanto aquelas do mundo árabe (Tunísia, Egito, Turquia), quanto aquelas do mundo ocidental (o movimento dos indignados na Espanha, as revoltas de Zuccotti Park nos Estados Unidos e, inclusive, as jornadas de junho de 2013 no Brasil) foram caracterizados, como aponta Butler (2015), por um contato entre corpos que dá lugar a um novo interregno espaço-temporal. É o que Landowski têm chamado de "alastramento", uma propagação de sentido que não corresponde "nem a uma empatia de ordem cognitiva, nem a um contagio viral, mas a uma expansão por contiguidade de elementos que se tocam entre si, à maneira de um incêndio em

\footnotetext{
2 Preciso que, em As Interações Arriscadas, Landowski, diferentemente de Greimas, trata separadamente o sensível e o aleatório, fazendo do primeiro o princípio regulador do regime do ajustamento e do segundo o princípio regulador do regime do acidente (Landowski, 2014, p. 73). No entanto, quando se analisam os acidentes que marcam o devir dos processos sociopolítico contemporâneos esta distinção faz-se mais opaca e torna-se indispensável considerar seus investimentos estésico-passionais. De resto, é o próprio Landowski que nos convida a seguir esta diretriz ao admitir, nas conclusões de As interações arriscadas, a necessidade de abordar conjuntamente regimes de sentido e interação e regimes passionais, refletindo, entre outras coisas, sobre as "paixões do acaso" (Landowski, 2014, p. 106).
} 
uma floresta" (Landowski, 2018, p. 15, trad. minha)3 , típicas, conforme sugere o autor, dos movimentos populistas contemporâneos. Em outros termos: a força do acidente, bem como a sua duração, é diretamente proporcional à "carga estésica" (cf. Demuru, 2019b) que o engendra e que ele se torna capaz de mobilizar. Como veremos mais adiante, as redes sociais cumprem, neste processo, um papel fundamental.

Por fim, há de se ressaltar a correlação entre acidente e indeterminação semântica. Vimos antes que Landowski atribui ao acidente um papel catastrófico, entendendo-o como causa do colapso do sistema de crenças e valores em jogo em um determinado horizonte narrativo. Ora, o regime de sentido ao qual dá origem este choque é, nas palavras do autor, o "sem sentido", a "insensatez" (Landowski, 2014, p. 71-80). Infere-se, portanto, que o acidente dá lugar a uma indeterminação semântica de caráter negativo.

Pág. 10, $2^{\circ}$ parágrafo - Onde se lê: "Em seus últimos escritos, [...] que o estudioso define 'explosões' (LOTMAN, 1995; 2009)", leia-se: "O conceito de explosão, postulado por Lotman no fim de sua trajetória intelectual (LOTMAN, 1995; 2009), entretém relações estritas com o acidente landowskiano".

Pág. 10, $4^{\circ}$ parágrafo, $2^{\mathrm{a}}$ linha - Deletar: "No momento em que George d'Anthès [...] até 'motivação adicional retroativa' (LOTMAN, 1995, p. 37, tradução nossa)".

Pág. 11, $3^{\circ}$ parágrafo - Deletar: linhas 8 a 12.

Pág. 11, $4^{\circ}$ parágrafo: Deletar: última frase do $4^{\circ}$ parágrafo.

Pág. 12, $1^{\circ}$ parágrafo - Deletar: "Como se fosse vivido 'fora do tempo, ainda que, na realidade, possa estender-se ao longo de um amplo espaço temporal' (LOTMAN, 2009, p. 158, tradução nossa)" e descartar também parte da última frase do parágrafo: [...] "como na releitura do conceito landowskiano de acidente que propus na seção anterior".

Pág. 12, $6^{\circ}$ parágrafo, $1^{\mathrm{a}}$ linha - Onde se lê: "Complementando-se reciprocamente", leia-se: "Dito isto, vejamos agora como" [...].

Pág. 12, $6^{\circ}$ parágrafo, $4^{\mathrm{a}}$ linha - Eliminar a última frase do parágrafo.

\footnotetext{
3 "Ni empathie d'ordre cognitif ni contagion virale mais expansion par contiguïté des éléments touchés, à la manière d'un incendie de forêt" (Landowski, 2018, p. 15).
} 
Pág. $16,2^{\circ}$ parágrafo, primeira linha - Onde se lê: “Dois são, portanto, os traços distintivos que diferenciam o discurso das jornadas de junho de 2013", leia-se: Dois são, portanto, os traços que distinguem - seja na semiosfera midiática, seja naquela das manifestações políticas - o discurso da e sobre as jornadas de junho de 2013 [...].

Pág. $16,2^{\circ}$ parágrafo, $4^{\mathrm{a}}$ linha - Onde se lê: "Surgidas nas redes sociais, ambas se espalham rapidamente em outras esferas discursivas", leia-se: Surgidas nas redes sociais e migradas, quase simultaneamente para as ruas, ambas se espaIham, em seguida, na esfera das velhas mídias" [...].

Página $17,1^{\circ}$ parágrafo, $3^{\mathrm{a}}$ linha - Onde se lê: [...] canalizada contra Dilma. Um exemplo disso são os panelaços que [...], leia-se: : [...] canalizada contra Dilma. É um processo que, nos termos de Landowski (2009), pode ser definido como uma "manipulação por contágio", ou seja, uma estratégia que visa persuadir o outro insistindo em uma comunicação marcadamente sensível. Um exemplo disso são os panelaços que [...].

Página $17,1^{\circ}$ parágrafo, $8^{\mathrm{a}}$ linha - Onde se lê: [...] profunda entre mídia e sociedade, entre a mídia e a vida real, que resulta em um novo acordo estésico. [...], leia-se: [...] profunda entre as semsiosferas da mídia, da política e da sociedade brasileira como um todo - ou, em outros termos, entre campo midiático, político e social (Rodrigues, 1999; Miguel, 2002; Fausto Neto, 2012; 2016) - que resulta em um novo acordo estésico nacional.

Página 17, $3^{\circ}$ parágrafo, linha única (intertítulo) - Onde se lê: "História, política e mídia: temporalidades cruzadas", leia-se: Junho de 2013: um acontecimento disruptivo.

Página 18, entre $04^{\circ}$ e $5^{\circ}$ parágrafos, acrescentar: Estudos recentes oriundos da área de comunicação seguem esta mesma hipótese. É o caso de Prado (2018), o qual, a partir de Badiou e Zilberberg, aborda o caráter acontecimental das jornadas, mostrando seu impacto na esfera política e midiática nacional. No entanto, tais afirmações não são suficientes. Ao mesmo tempo, é importante mostrar como tal processo acidental/explosivo se articula. É esta, pois, a maior contribuição que a perspectiva sociossemiótica pode oferecer tanto ao campo das ciências sociais, quanto àquele dos estudos comunicacionais.

Página 18, após o parágrafo acima acrescentado, incluir o intertítulo: 
No lapso entre implosão e explosão: a vagueza e a carga estésica

Página 19, $2^{\circ}$ parágrafo, $\quad 5^{a}$ linha - Onde se lê: [...] "proliferação de novos significados, sejam positivos, sejam negativos.", leia-se:[...] "proliferação, nas ruas, nas velhas mídias e na sociedade de modo geral, de novos significados, sejam positivos, sejam negativos".

Página $19,3^{\circ}$ parágrafo, $12^{\mathrm{a}}$ linha - Onde se lê: "[...] a primeira quanto as segundas é a mesma. [...]", leia-se: “[...] a primeira quanto as segundas é a mesma.

Página 21, $4^{\circ}$ parágrafo, $19^{a}$ linha - Onde se lê: [... "proponho de chamar hiperpresentista", leia-se: [...] "proponho de chamar hiperpresentista fractal". 